\title{
COVID-19 and Sexuality: Reinventing Intimacy
}

\author{
Gerson Pereira Lopes ${ }^{1} \cdot$ Fabiene Bernardes Castro Vale $^{2} \cdot$ Isabela Vieira $^{1} \cdot$ Agnaldo Lopes da Silva Filho $^{2}$. \\ Catarina Abuhid ${ }^{1}$. Selmo Geber ${ }^{2}$ (I)
}

Received: 12 June 2020 / Revised: 3 July 2020 / Accepted: 6 July 2020 / Published online: 21 July 2020

(c) Springer Science+Business Media, LLC, part of Springer Nature 2020

On March 11, 2020, the World Health Organization (WHO) declared the coronavirus disease (COVID-19) a pandemic. Since then, all federal and local authorities as well as regulatory agencies have asserted and developed robust policies in order to reduce the spread of the disease, worsening of clinical presentation and deaths related to the infection with the severe acute respiratory syndrome coronavirus 2 (SARS-CoV-2), the virus responsible for COVID-19. SARS-CoV-2 is transmitted from person to person through respiratory droplets when the distance is up to $2 \mathrm{~m}$. Contagion may also occur after touching an infected surface followed by touching eyes, nose or mouth (Stadnytskyi, Bax, Bax, \& Anfinrud, 2020). Although less expressive, other chances of infection may happen through contact with blood, feces, and semen of a contaminated person (Cheung et al., 2020; Li, Jin, Bao, Zhao, \& Zhang, 2020; Yu et al., 2020). As a strategy to prevent the dissemination of SARS-CoV-2, the WHO (2020) recommended personal preventive measures (hand/respiratory hygiene, cough etiquette, facial coverings, cleaning/disinfection of environments) and social measures, namely social/physical distancing and stayat-home requests. These precautions led to social distancing. As a consequence, sexual contact has been discouraged, as it might increase the risk of transmission of SARS-CoV-2, mainly for those who do not live together. On the other hand, for those who do live together, the effects of social isolation can impose variable impacts on sex life (Turban, Keuroghlian, \& Mayer, 2020).

Considering the limited number of studies published on sexual health during the pandemic, we understand that a special approach must be taken. Until there is an alternative to stop COVID-19 transmission other than social distancing, it

Selmo Geber

selmogeber@origen.com.br

1 Department of Sexual Medicine, Hospital Mater Dei, Belo Horizonte, Brazil

2 Department of Obstetrics and Gynaecology, Universidade Federal de Minas Gerais, Av Alfredo Balena 190, Belo Horizonte, Minas Gerais, Brazil is important to offer specific advice on patients' sexual health. Therefore, our objective is to suggest counseling on sexual behavior during the pandemic.

\section{People with No Steady Sexual Partner}

Considering the WHO guidance on social distancing, sexual abstinence is the approach with the lowest risk during the pandemic, for those who do not have a steady sexual partner. However, as this is not a desirable alternative for most people, a safe recommendation for patients to meet their sexual needs, without the risk of SARS-CoV-2 infection (Turban et al., 2020), could be masturbation. According to Kaplan (1974), sexual pleasure is a construction, and thus, masturbation should fulfill the objectives of "sexual fantasy" and "friction" (the touch). Besides, quarantine time can be seen as an opportunity to create new fantasies, discover preferences for genital touch, and learn more about sex through podcasts, documentaries, films, and educational materials.

It is already known that the sexual response starts with sexual motivation (Kaplan, 1974). Motivation can be triggered by sexual fantasy, which in turn triggers spontaneous desire that is followed by subjective arousal. After physical self-stimulation, genital arousal is increased so that orgasmic response and sexual satisfaction may be achieved (Basson, 2001). The knowledge of sexual response leaves no doubt that the period of social isolation can be used productively in sex life. Spending time at home is an opportunity to better understand the functioning of the body and to find new ways to experience pleasure alone. It is a unique invitation to return to oneself, to learn how to nurture a good relationship with one's own body and with other people.

This is not the time to seek a new partnership for sex, but perhaps it can be the chance to meet new people online, create new bonds and maybe, when social distancing is over, get to know others even better. In a study involving 15,738 adults, Regnerus, Price, and Gordon (2017) reported that satisfaction with sex life and partnership status were stronger predictors of 
masturbation than sex itself. The study also showed that older people may be more likely to masturbate if they do not have a partner or if the partner is unwilling or unable to engage in sex. This is quite important, since this is the main risk group for COVID-19. This study also demonstrated the importance of sexual fantasy/subjective desire as a potential mediator for a fulfilling sexual response.

\section{People Living Apart from Steady Partners}

Partners who do not live together can adopt a new sexual routine. If, due to the pandemic, people have changed their work routine, why not reinvent sexual intimacy?

It is recommended to leave home only for essential needs. However, sexual activity is currently at the bottom of the list as one can be exposed to the virus by physical proximity and, although it is not a sexually transmitted infection, activities such as kissing and, theoretically, cunnilingus and anal sex could also involve risk. Since even asymptomatic carriers may spread SARS-CoV-2, traditional sexual intercourse is not a safe option. Therefore, it is necessary to address other alternatives of exploring sexuality. New models of sexual experiences such as sexting and sharing photographs or videos can enrich sex life and encourage the use of sexual imagination/fantasy. Sexual experience is a complex interplay of physical, visual, auditory, and psychological stimuli, which does not necessarily require physical contact.

In summary, partners physically separated due to social distancing can be advised to awaken other sources of pleasure and create new habits such as playing sexual games, sharing existing fantasies, and seeking other remote sexual stimuli. It is possible to ensure personal safety and contribute to the control of the pandemic while reinventing intimacy with each other.

\section{Partners in Isolation Together}

In this group, if partners are asymptomatic and have strictly followed isolation restrictions, there is no problem in maintaining sexual intercourse. However, it is essential that special care and precaution are rigorously taken, as it is possible that infection may occur and one becomes an asymptomatic carrier.

One of the first published studies on sexual behavior during the pandemic described the results of an online questionnaire on sexual behavior throughout April 2020. The results showed that $45 \%$ of the participants reported that isolation had an impact on sex life, $72.5 \%$ reported having sex 1 to 5 times a week, an increase of $3.3 \%$ in sexual activity compared to before the pandemic, and $50 \%$ reported having positive changes in their emotional bonds. The small increase in sexual engagement might be explained by the search for intimacy and security or the increase in availability (Arafat, Alradie-Mohamed, Kar, Sharma, \& Kabir, 2020).
Many partners living together spend most of the day or allday coexisting. Many challenges arise from excessive time living together and sharing domestic chores, respecting privacy and individuality, and confronting opposing habits. The routine that once was taken for granted had to change, becoming a source of stress. Impositions of new forms of work, restrictions on leaving home, financial instability, among countless other changes, take on main roles, and sex life becomes a pleasant reminder of an already distant past.

For some people, being confined at home with the partner is an indisputable premise for sexual intercourse. For others, the situation is so unstable that sex does not come to mind. Some want to do it to relax and so many others do not want "one more thing to worry about." Unlike the past, today's crisis no longer chooses the gender to be affected. In scenarios of instability, men's libido can be impacted as much as women. Desire is a complex operation that needs several conditions to arise. Amid the sudden change in habits, these conditions may be much more present (high stress generates a high search for immediate pleasure) or completely absent (loss of sense of security and stability).

How to solve the desire equation when its roots are so antagonistic? The best alternative is to refine communication and strengthen intimacy. If the ability to communicate openly has been lost, now is the time to regain it. Communicational intelligence is based on honesty, self-knowledge, kindness, and humility. First, it is necessary to recognize one's own desires and preferences. Then one needs to see in the partner someone with whom one can openly share these feelings. Finally, in a gentle and humble way, one can share how one's own desire works and why it is important to have or stop having sex, without expecting the partner to work the same way. Emotional intimacy is a positive affection exchange that requires respect, companionship, and good communication (Basson, 2001). Therefore, the challenges of living together can interfere in the quality of sexual exchange. For a natural and pleasurable sex, it is necessary that all affection exchange be positive with good communication, respect and companionship.

\section{Reinventing Intimacy}

The new coronavirus pandemic presents obstacles to sexuality in several ways for those who have a steady sexual partner or not. In the face of all the uncertainties caused by this still poorly understood virus, it is normal to feel disturbed and insecure while facing the threat of contamination. Fear of contagion also interferes with intimacy between partners. Jacob et al. (2020) assessed 868 participants who responded to an online questionnaire and described that during self-isolation/social distancing, 39.9\% reported engaging in sexual activity at least once a week, thereby being classified as sexually active. There was a particularly high prevalence of sexual activity among young 
male adults, with married/stable relationships, employed with high annual family income and who had recreational use of alcohol. In addition, the prevalence of sexual activity increased significantly from $33.5 \%$ in people who were self-isolated for 0-5 days to $47.0 \%$ in those who were self-isolated for more than 11 days.

This study illustrates the present scenario in which partners who cohabit in confinement may have greater intimacy, resulting in a positive change in sexual behavior. The factors associated with an increase in sexual intimacy are: more time spent together, less stress at work, absence of outdoor recreation, and less social or family obligations. Erotic and/or sexual intimacy has been discussed by health agencies in different countries, highlighting the significant role of sexuality in mental health.

It has been demonstrated that psychosocial support of good quality relationships can be the protection mechanism against mortality (Holt-Lunstad, Smith, \& Layton, 2010). Robles, Slatcher, Trombello, and McGinn (2014) performed a metaanalysis, demonstrating that adults who reported higher quality of relationship as a consequence of the strengthening of intimacy had better physical functioning and longevity. Likewise, the frequency of sexual intimacy of individuals in relationships has been associated with better mental and physical health outcomes, such as greater happiness, general well-being, and greater satisfaction with life (Muise, Schimmack, \& Impett, 2016).

It is true that COVID-19 has been responsible for delaying many meetings; however, at the same time, it has allowed many partners to have intimacy for longer than usual. Isolation time is an invitation to learn to live better together. Each relationship works differently, according to their own contracts and limits. Hence, there is no special formula for perfect coexistence, but time for two can be used to improve communication, set boundaries, share tasks, experience leisure activities, and reinvent intimacy. The current scenario proves to be opportune for the development of necessary skills for modern relationships where all have equal rights and duties. So, it is necessary to cooperate, respect one's individuality, learn to manage crises, and reinvent sexual life.

\section{Mental and Sexual Health}

Social isolation and the fear of contracting SARS-CoV-2 virus can directly affect the physical and psychological health of individuals and may have a negative impact on health in general. Furthermore, coexisting problems can be an extra disturbance not only in mental health but also in sexual health. A relationship that presents frequent interpersonal conflicts, poor communication, hostility, impatience, and lack of privacy tends to increase stress and worsen health over time. Negative perceptions and performances of a relationship affect the biological experience of stress and bring consequences for physical and mental health. On the other hand, positive perceptions and performances, such as responsiveness, support, and intimacy, are usually associated with reduced response to stress and improvement in general health (Farrell \& Simpson, 2017).

The changes imposed by the pandemic leads to the need for reorganization in all spheres. Uncertainty in the global scenario is a very stressful factor, a source of anguish and suffering for billions of people who have been deprived of social contact, have had to adapt their professional lives and have seen their financial lives turned upside down. It is necessary to reinvent oneself in all different aspects, looking for new ways to do one's jobs, organize one's routines, and relate to others.

\section{Conclusion}

As science tries to develop, as fast as possible, a solution for COVID-19, social distancing is still the best measure to be taken. It is recommended that partners who live separately reinvent loving and sexual relationships. For those who live together, it is recommended to strengthen intimacy. A highquality relationship is beneficial for physical, mental, and sexual well-being. On the other hand, a troubled, negative relationship generally induces greater responses to stress and worse mental and sexual health.

Surely, it is still too early to predict the consequences of the pandemic regarding sexuality. Physical proximity and touch are seen with great discomfort and physical contact has never been more discouraged. Human sexual response to stimuli that trigger sexual desire is a motivational cycle based on intimacy, which includes subjective experiences (Basson, 2015). Therefore, advising on new forms of intimacy, during these uncertain times, is of great importance for sexual health, as well as for general well-being.

Funding This study was not funded.

\section{Compliance with Ethical Standards}

Conflict of interest The authors declare that they have no conflict of interest.

\section{References}

Arafat, S., Alradie-Mohamed, A., Kar, S. K., Sharma, P., \& Kabir, R. (2020). Does COVID-19 pandemic affect sexual behaviour? A cross-sectional, cross-national online survey. Psychiatry Research, 289, 113050. https://doi.org/10.1016/j.psychres.2020.113050.

Basson, R. (2001). Using a different model for female sexual response to address women's problematic low sexual desire. Journal of Sex and Marital Therapy, 27(5), 395-403. https://doi.org/10.1080/71384 6827. 
Basson, R. (2015). Human sexual response. Handbook of Clinical Neurology, 130, 11-18. https://doi.org/10.1016/B978-0-444-63247 $-0.00002-X$.

Cheung, K. S., Hung, I. F., Chan, P. P., Lung, K. C., Tso, E., Liu, R., ... Yip, C. C. (2020). Gastrointestinal manifestations of SARS-CoV-2 infection and virus load in fecal samples from a Hong Kong cohort: Systematic review and meta-analysis. Gastroenterology, S00165085(20), 30448. https://doi.org/10.1053/j.gastro.2020.03.065.

Farrell, A. K., \& Simpson, J. A. (2017). Effects of relationship functioning on the biological experience of stress and physical health. Current Opinion in Psychology, 13, 49-53. https://doi.org/10.1016/j.copsyc.2016.04.014.

Holt-Lunstad, J., Smith, T. B., \& Layton, J. B. (2010). Social relationships and mortality risk: A meta-analytic review. PLoS Medicine, 7(7), e1000316. https://doi.org/10.1371/journal.pmed.1000316.

Jacob, L., Smith, L., Butler, L., Barnett, Y., Grabovac, I., McDermott, D., ... Tully, M. (2020). COVID-19 social distancing and sexual activity in a sample of the British public. Journal of Sexual Medicine. https ://doi.org/10.1016/j.jsxm.2020.05.001.

Kaplan, H. S. (1974). The new sex therapy. New York: Brunner/Mazel.

Li, D., Jin, M., Bao, P., Zhao, W., \& Zhang, S. (2020). Clinical characteristics and results of semen tests among men with coronavirus disease 2019. JAMA Network Open, 3(5), e208292. https://doi.org/10.1001/ jamanetworkopen.2020.8292.

Muise, A., Schimmack, U., \& Impett, E. A. (2016). Sexual frequency predicts greater well-being, but more is not always better. Social Psychological and Personality Science, 7(4), 295-302. https://doi. org/10.1177/1948550615616462.

Regnerus, M., Price, J., \& Gordon, D. (2017). Masturbation and partnered sex: Substitutes or complements? Archives of Sexual Behavior, 46(7), 2111-2121. https://doi.org/10.1007/s10508-017-0975-8.
Robles, T. F., Slatcher, R. B., Trombello, J. M., \& McGinn, M. M. (2014). Marital quality and health: A meta-analytic review. Psychological Bulletin, 140(1), 140-187. https://doi.org/10.1037/a0031859.

Stadnytskyi, V., Bax, C. E., Bax, A., \& Anfinrud, P. (2020). The airborne lifetime of small speech droplets and their potential importance in SARS-CoV-2 transmission. Proceedings of the National Academy of Sciences of the United States of America, 117(22), 11875-11877. https://doi.org/10.1073/pnas.2006874117.

Turban, J. L., Keuroghlian, A. S., \& Mayer, K. H. (2020). Sexual health in the SARS-CoV-2 era. Annals of Internal Medicine. https://doi. org/10.7326/M20-2004.

World Health Organization. (2020, 16 April). Considerations in adjusting public health and social measures in the context of COVID-19: Interim guidance. Retrieved from https://apps.who.int/iris/handl e/10665/331773.

Yu, F., Yan, L., Wang, N., Yang, S., Wang, L., Tang, Y., ... Wang, F. (2020). Quantitative detection and viral load analysis of SARSCoV-2 in infected patients. Clinical Infectious Diseases. https://doi. org/10.1093/cid/ciaa345.

Publisher's Note Springer Nature remains neutral with regard to jurisdictional claims in published maps and institutional affiliations. 